\title{
PATLATMA KAYNAKLI YER SARSINTISI VE HASAR DEĞERLENDİRME PARAMETRELERİ
}

\author{
${ }^{1}$ Bilgehan KEKEÇ ${ }^{(D)}$, ${ }^{2}$ Dhikra GHILOUFI ${ }^{(D)}$ \\ 1,2 Konya Teknik Üniversitesi, Mühendislik ve Doğa Bilimleri Fakültesi, Maden Mühendisliği Bölümü, \\ Konya, TÜRKIYY \\ 1bkekec@ktun.edu.tr, 2ghiloufi.dhikra@gmail.com
}

\section{(Geliş/Received: 26.06.2020; Kabul/Accepted in Revised Form: 16.08.2020)}

ÖZ: Patlatmalı işlemleri madencilik, tünel açma faaliyetleri, inşaat ve yıkım işlemleri ve enerji sektörü gibi birçok sektörde yoğun olarak kullanılmaktadır. Bu yöntem hız ve ekonomik yönden çok verimli bir yöntem olmasına rağmen çeşitli çevresel etkilere ve büyük hasarlara neden olabilmektedir. Çevreye verilen olumsuz etkilerin en önemlisi zemin titreşimleri olup, oluşan titreşimin şiddetine ve etki alanına göre maddi kayıplara ve hatta can kayıplarına sebep olabilmektedir. Bu sebeple muhtemel etkilerin en aza indirilmesi ya da en iyi ihtimalle bertaraf edilmesi için patlatma faaliyetlerinde zemin titreşimlerinin özel olarak irdelenmesi gerekmektedir.

$\mathrm{Bu}$ çalışmada patlatmadan kaynaklı zemin titreşimlerinin özellikleri, sınıflandırılması ve temel büyüklükleri sunulmuştur. Ayrıca, yer sarsıntısının yapılar üzerinde oluşturduğu hasarlar, insanlar üzerindeki olumsuz etkiler ve insan algısı ile yapısal hasar arasındaki ilişki detaylı bir şekilde araştırılmıştır. Ayrıca, patlatmadan kaynaklanan sismik dalgalar, arazi katmanları ve yapılar arasındaki etkileşimler irdelenmiş ve Parçacık Hızı (PPV), Bileşke Vektörel Toplamı PVS (Peak Vector Sum), parçacık yer değiştirmesi, parçacık ivmesi ve frekans başta olmak üzere yer sarsıntısı hasarının değerlendirmesinde sıkça kullanılan parametreler sunulmuştur.

Anahtar Kelimeler: Patlatma, Çeoresel etkiler, Yer sarsıntısı, Hasar Parametreleri.

\section{Blast-Induced Ground Vibration and Damage Assessment Parameters}

\begin{abstract}
Blasting operations are extensively practiced in mining, tunneling activities, construction and demolition projects and the energy sector. However, despite the efficiency of this method in terms of time and costs, blasting operations can generate numerous environmental impacts and major damages. Ground vibration is the most detrimental impact caused by blasting activities as it can cause material loss and even the loss of human lives depending on its intensity and impact area. Thus, ground vibrations should be thoroughly investigated in order to minimize or ideally prevent their possible impacts.

This study examines the characteristics of blast-induced ground vibrations and investigates the properties and types of the body and surface waves resulting from blasting activities. In addition, structural damages caused by ground vibrations, their negative impacts on human health and the relationship between human perception and structural damages are presented in details. Furthermore, the study highlights the interaction mechanisms between seismic waves, ground layers and structures and investigates the most commonly used parameters in the assessment of ground vibration damages i.e. Peak Particle Velocity PPV, Peak Vector Sum PVS, particle displacement, particle acceleration and frequency.
\end{abstract}

Key Words: Blasting, Environmental impacts, Ground vibration, Damage Parameters. 


\section{GİRİŞ (INTRODUCTION)}

Teknolojinin gelişmesi ve nüfusun artmasıyla birlikte hammadde gereksinimi de artmaktadır. Artan hammadde ihtiyacı, önceden ekonomik olmayan veya yerleşim yerlerine yakın bölgelerde oluşum gösterdiği için değerlendirilmeyen maden sahalarını da işletmeye açma gereği doğurmuştur. Maden sahalarında bilinen en ekonomik üretim yöntemi delme patlatma yöntemidir (Bilim ve ark. 2016, Singh, 2012, Aksoy ve Yalçın, 1999,). Patlatma, hız ve ekonomik yönden, çok verimli bir yöntem olmasına rağmen, özellikle çalışma bölgesi yakınlarında çeşitli çevresel etkilere ve büyük hasarlara neden olabilmektedir. Böylece yerleşim yerleri, baraj, yol, tünel, boru hattı, sit alanları yakınlarında yapılacak olan üretim patlatmalarında özel tedbirler alınması zorunludur. Çünkü patlatma sonucunda oluşan enerjinin önemli bir kısmı çevresel etkilere neden olan faydasız enerji olarak karşımıza çıkabilmektedir. Patlatmanın neden olduğu temel çevresel sorunlar; titreşim (yer sarsıntısı), hava şoku, toz ve gaz oluşumu, gürültü ve kaya fırlamasıdır (kaya savrulması). Bu çevreye verilen olumsuz etkilerin en önemlisi zemin titreşimleridir. Oluşan bu sarsıntılar tıpkı deprem dalgaları gibi kayaç özelliklerine bağlı olarak çok uzaklara taşınabilme özelliğine sahiptir. Oluşan titreşimin şiddetine ve etki alanına göre hem maddi kayıplara hem de can kayıplarına sebebiyet vermektedir.

Yer sarsıntısı insan rahatsızlığına, hassas ekipmanların arızalanmasına, yapısal hasarlara ve hatta can kayıplarına neden olabilmektedir. Bu sebeple, madencilik ve inşaat kazılarının temelini oluşturan patlatma faaliyetlerinin zemin titreşimlerinin özel olarak irdelenmesi gerekmektedir.

$\mathrm{Bu}$ çalışmada, patlatmadan kaynaklı zemin titreşimlerinin özellikleri, sınıflandırılması ve temel büyüklükleri sunulmuş, yer sarsıntısı hasarının değerlendirmesinde sıkça kullanılan parametreler anlatılmışır.

\section{PATLATMA SONUCUNDA OLUŞAN YER SARSINTILARI (BLAST-INDUCED GROUND VIBRATIONS)}

Yer sarsıntısı, suya düşen taş çarpmalarından dolayı dışa doğru yayılan dalgacıklar gibi patlama noktasından dışarı doğru yayılan bir dalga hareketidir (Elevli \& Arpaz, 2010). Bazı referanslar, doğal afetler (depremler, fırtınalar) veya insan kaynaklı (patlatma, inşaat faaliyetleri, trafik, kazılar, nükleer testler ve ulaşım araçları gibi) bir sonuç olarak zemin titreşimini tanımlasa da (Duarte, Misael, \& Filho, 2002), genel olarak, herhangi bir doğal fenomen hariç insan kaynaklı faaliyetler tartışlırken zemin titreşimi veya yer sarsıntısı terimi kullanılmaktadır (Srbulov, 2008).

İnsanların rahatsızlığına, hassas ekipmanların arızalanmasına ve yapısal hasarlara neden olabilecek insan yapımı zemin titreşim kaynakları; patlatma, madencilik işlemleri, inşaat faaliyetleri, trafik, petrol arama faaliyetleri, makinaların çalışması ve nükleer testler gibi aktivitelerden kaynaklıdır. Patlatma etkisiyle oluşan zemin titreşimi diğer insan yapımı kaynaklara kıyasla daha kısa sürmektedir. Ayrıca patlatma sonucunda oluşan zemin titreşimleri daha geniş bir frekans bandı $(1-300 \mathrm{~Hz})$ ve daha yüksek parçacık ivmesiyle $\left(0,02-50 \mathrm{~m} / \mathrm{s}^{2}\right)$ karakterize edilmektedir (Çizelge 1).

Çizelge 1. Bazı insan kaynaklı zemin titreşimlerinin özellikleri (ISO, 2010) Table 1. Characteristics of some man-made ground vibrations (ISO, 2010)

\begin{tabular}{|c|c|c|c|}
\hline Titreşim kaynağı & $\begin{array}{c}\text { Frekans band1 } \\
(\mathrm{Hz})\end{array}$ & $\begin{array}{l}\text { Parçacık hız aralığı } \\
(\mathrm{mm} / \mathrm{s})\end{array}$ & $\begin{array}{l}\text { Parçacık ivme aralığ } 1 \\
\left(\mathrm{~m} / \mathrm{s}^{2}\right)\end{array}$ \\
\hline Trafik (yol ve demiryolu) & $1-100$ & $0,2-50$ & $0,02-1$ \\
\hline Patlatma & $1-300$ & $0,2-100$ & $0,02-50$ \\
\hline Kazı & $1-100$ & $0,2-100$ & $0,02-2$ \\
\hline Makinalar & $1-100$ & $0,2-100$ & $0,02-1$ \\
\hline
\end{tabular}




\section{Sismik Dalgaların Özellikleri ve Sınıflandırılması (Propertıes and Classıfıcatıon of Seısmıc Waves)}

Depremler gibi doğal veya patlatma, trafik faaliyetleri, kazılar ile nükleer testler gibi insan kaynaklı sismik kaynaklardan üretilen enerji (zemin titreşimi), deprem dalgaları aracılığıyla ortamda yayılmaktadır. Sismik dalgalar olarak daha yaygın olarak adlandırılan bu deprem dalgaları mekanik dalgalardır ve sadece maddesel ortamlarda hareket edebilmektedir.

Elastik dalgalar olarak da bilinen bu sismik dalgalar yeryüzünün katmanlarında cisim dalgaları (body waves) olarak yayılabilir veya yüzey boyunca yüzey dalgaları (surface waves) olarak ilerleyebilir (Wu \& $\mathrm{Wu}, 2008)$. Cisim dalgaları Birincil (P) ve İkincil (S) dalgaları kapsamaktadır. Yüzey dalgaları ise Rayleigh (R) ve Love (L) dalgalarına ayrılmaktadır (Sudarshan, t.y.).

1.1. Sismik dalgalara ait temel büyüklükler

Sismik dalgaların temel büyüklükleri; Tepe, çukur, genlik (A), dalga boyu ( $\lambda)$, frekans $(f)$, periyot (T), hız (v) ve açısal frekansdır ( $\omega$ ) (Moğulkoç ve ark., 2017) (Şekil 1).

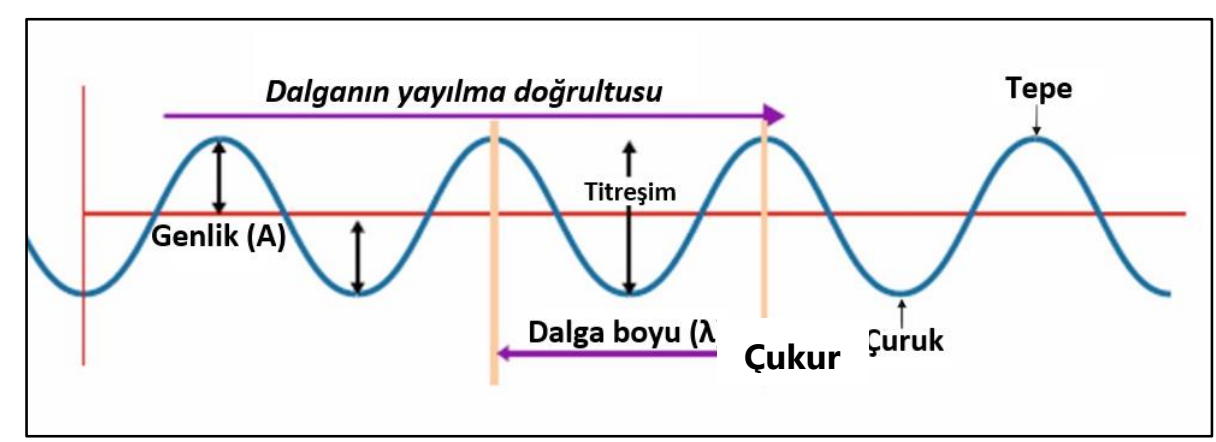

Şekil 1. Sismik dalgaların temel büyüklükleri (Enine Dalgalar için)

Figure 1. The basic magnitudes of seismic waves (for Transverse Waves)

Tepe (Crest) ve çukur (Trough) : Enine dalgalar için tepe noktası maksimum pozitif titreşimi gösteren nokta (en üst nokta) ve çukur noktası maksimum negatif titreşimi gösteren noktadır (en alt nokta). Boyuna dalgalar için tepe noktası, sıkışık bölgelere denk gelir ancak çukur noktası seyrek bölgeye karşılık gelmektedir.

$>$ Genlik (A) (Amplitude): Genlik, dalganın taşıdığı enerji miktarının bir göstergesidir. Böylece, daha yüksek bir genlik daha yüksek taşınan enerji anlamına gelmektedir ve ayn şekilde düşük genlik, düşük taşınan enerjiyi göstermektedir. Enine dalgalar için genlik, denge pozisyonundan tepe veya çukur noktasına dik mesafedir yani maksimum uzaklıktır. Ancak, boyuna dalgalar için sıkışık ve seyrek bölgeler arasındaki farktır. Boyuna dalgalar için, sıkışma yoğunluğu arttıkça genlik artmaktadır.

$>$ Dalga boyu $(\lambda)$ (Wavelength): Lambda $(\lambda)$ ile gösterilen ve metre ya da Angström $\left(\mathrm{A}^{0}\right)$ cinsiden ifade edilen dalga boyu, enine dalgalar için, iki ardışık tepe veya iki ardışık çukur arasındaki uzaklıktır. Ancak, boyuna dalgalar için, dalga boyu iki ardışık iki sıkışık veya iki ardışık seyrek bölge arasındaki uzaklıktır.

$1 \mathrm{~A}^{0}=10^{-10} \mathrm{~m}$

$>$ Frekans $(f)$ (Frequency): Hertz $(\mathrm{Hz})$ cinsinden ifade edilen frekans, bir noktadan geçen saniyedeki dalga sayısını temsil etmektedir. Dalga boyu uzadıkça, frekans azalmaktadır.

1 cps (cycle per second) $=1 \mathrm{~Hz}$ (cps: saniye başına döngü)

$>$ Periyot (T) (Period): (T) ile gösterilen ve (s) ile ifade edilen periyot, ortamda bir parçacık tarafından tam bir dalganın tamamlanması için gereken süredir.

$>\operatorname{Hız}(v)$ (Velocity): Dalganın ilerleme hızı, dalga boyuna ve ortamın fiziksel özelliklerine bağlıdır. $(\mathrm{m} / \mathrm{s})$ cinsinden ifade edilen dalganın hızı aşağıda belirtilen formül kullanılarak hesaplanır:

$v(\mathrm{~m} / \mathrm{s})=f(\mathrm{~Hz}) \times \lambda(\mathrm{m})$

$>$ Açısal frekans $(\omega)$ (Angular frequency): Açısal frekans radyan/saniye birimi ile ifade edilen frekanstır. 
Çizelge 2'de sismik dalgaların büyüklüklerinin arasındaki ilişkileri sunulmaktadır. Şekil 2 bir zaman tanım aralığında patlatma neticesinde oluşan tipik yer sarsıntısının bir örneğini göstermektedir.

Çizelge 2. Dalga parametreleri arasındaki ilişkiler (Bormann, 2012)

Table 2. Relationships between wave parameters (Bormann, 2012)

\begin{tabular}{|l|l|l|}
\hline Parametre & Simge & Illişkiler \\
\hline Periyot & $\mathrm{T}$ & $\mathrm{T}=1 / f=2 \pi / \omega=\lambda / v$ \\
\hline Frekans & $f$ & $f=1 / \mathrm{T}=\omega / 2 \pi=v / \lambda$ \\
\hline Açısal frekans & $\omega$ & $\omega=2 \pi f=2 \pi / \mathrm{T}=v \cdot \mathrm{k}$ \\
\hline Hiz & $v$ & $v=\lambda / f=f \lambda=\omega / \mathrm{k}$ \\
\hline Dalga boyu & $\lambda$ & $\lambda=v / f=v \cdot \mathrm{T}=2 \pi / \mathrm{k}$ \\
\hline Dalga sayısı & $\mathrm{k}$ & $\mathrm{k}=\omega / v=2 \pi / \lambda=2 \pi f / v$ \\
\hline
\end{tabular}

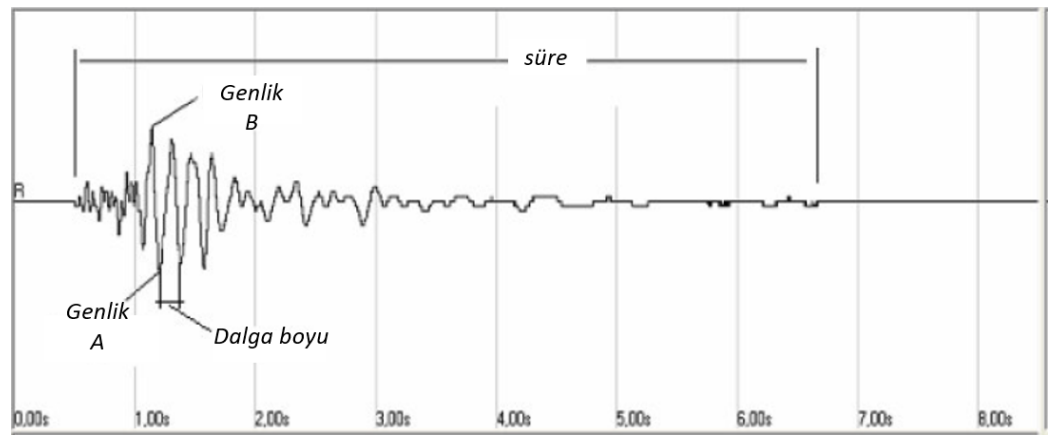

Şekil 2. Bir zaman tanım aralığında patlatma neticesinde oluşan tipik yer sarsıntısı (Dowding, 1985) Figure 2. Typical blast vibration time history (Dowding, 1985)

\section{YER TITTREŞIMMLERINIIN ETKİLERİ (IMPACTS OF GROUND VIBRATIONS)}

Bu başlık altında, insanların patlatma kaynaklı yer sarsıntılarına tepkileri ve yer sarsıntısının yapılar üzerinde oluşturduğu hasarlar anlatılmaktadır.

İnsanların patlatma kaynaklı yer sarsıntılarına tepkileri (Human reactions to blast-induced ground vibrations)

Zemin titreşimlerinin insanlar üzerindeki olumsuz etkileri (Adverse effects of ground vibrations on humans)

Zemin titreşimlerinin insanlar üzerindeki olumsuz etkileri psikolojik ve fizyolojik etki olarak ikiye ayrılmaktadır. Patlatma neticesinde oluşan yer sarsıntısının insanlar üzerinde psikolojik etkisinin değerlendirilmesi önemlidir. Ancak bu öznel bir konudur çünkü yer sarsıntısının psikolojik etkisi patlatma anında insanın konumu, etkinliği (ayakta, oturmada, uyanık, uykuda) ve hatta ruh haline bağlıdır. Yüksek titreşim algıları nedeniyle insanlar, herhangi bir zemin titreşiminin zarar verdiğini düşünürken, bu zemin titreşimlerinin çoğu hasar eşiğinin altındadır.

İnsan algısı, titreşimin frekansına ve şiddetine bağlıdır. İnsan vücudu, özellikle 1 ila $100 \mathrm{~Hz}$ arasındaki düşük frekans aralığında zemin titreşimlerine karşı son derece hassastır (Transport and Road Research Laboratory Department of Transport, 1986).

Literatürde zemin titreşimine bağlı olarak insan algısı ile ilgili birçok çalışma mevcuttur. Örneğin Çizelge 2.3'te kısa süreli zemin titreşimlerinin insanlar üzerindeki etkileri vurgulanmaktadır (Oriard \& Emmert, 1980). Çizelge 4'te ise hem titreşimin frekansını hem de PPV'yi dikkate alarak patlatma sonucunda oluşan zemin titreşimin insan üzerindeki tepkisini değerlendirmek için yeni bir kriter sunmaktadır (Peng et al., 2017). 
Çizelge 3. Kısa süreli zemin titreşimlerinin insanlar üzerindeki etkileri (Oriard \& Emmert, 1980)

Table 3. Effects of transient ground vibrations on humans (Oriard \& Emmert, 1980)

\begin{tabular}{|l|l|l|}
\hline İnsanlar üzerindeki etkileri & PPV seviyeleri $\mathbf{( m m} / \mathbf{s})$ \\
\hline Fizyolojik hasar & Tehlike & $101,6-254$ \\
\cline { 2 - 3 } & Risk & $50,8-101,6$ \\
\hline Şiddetli / tolerans eşiği & $30,5-50,8$ \\
\hline \multirow{3}{*}{ Rahatsızlık } & Çok rahatsız edici & $25,4-30,5$ \\
\cline { 2 - 3 } & Rahatsız edici & $10,2-25,4$ \\
\hline \multirow{3}{*}{ Fark edilebilir } & Şiddetle algılanabilir & $2,5-10,2$ \\
\cline { 2 - 3 } & Kesinlikle algılanabilir & $1,5-2,5$ \\
\cline { 2 - 3 } & Ancak algılanabilir & $0,25-1,5$ \\
\hline
\end{tabular}

Çizelge 4. Zemin titreşimlerinin insanlar üzerindeki etkileri (Peng et al., 2017) Table 4. Effects of ground vibrations on humans (Peng et al., 2017)

\begin{tabular}{|l|l|l|l|}
\hline \multirow{2}{*}{ İnsanlar üzerindeki etkileri } & \multicolumn{3}{|c|}{$\mathbf{P P V} \mathbf{( m m} / \mathbf{s})$} \\
\cline { 2 - 4 } & $<\mathbf{1 0} \mathbf{~ H z}$ & $\mathbf{1 0 - 5 0} \mathbf{~ H z}$ & $>\mathbf{5 0 ~} \mathbf{~ H z}$ \\
\hline Fizyolojik hasar & $50,9-78$ & $78-95,5$ & $95,5-119,4$ \\
\hline Şiddetli / tolerans eşiği & $15,9-23,9$ & $23,9-27,9$ & $27,9-39,8$ \\
\hline Rahatsılık/ rahatsı edici & $1,59-2,39$ & $2,39-6,37$ & $6,37-7,96$ \\
\hline Fark edilebilir/ algılanabilir & $0,03-0,08$ & $0,08-0,11$ & $0,11-0,16$ \\
\hline
\end{tabular}

Farklı çalışmalar tarafından geliştiren yer sarsıntılarında insan algısıyla ilgili kriterlere rağmen, bu konuya birçok parametre etki ettiği için karmaşık ve öznel bir konudur. Etkili bu parametreler, kişinin olay sırasında yapının içindeki veya dışındaki bulunduğu yeri (çünkü içerdeki insanlar zemin titreşimini dışarıdakilerden daha çok algılar), yaptığı aktiviteyi, kişiliğini, ruh halini ve yerel topluluğun patlatma projesine karşı sosyal tutumunu (çünkü bir proje bir topluluk tarafından memnuniyetle karşılanmadığında, patlatma faaliyetleri istenmez) (Society of Explosives Engineers, t.y.) kapsamaktadır. Ayrıca, zemin titreşiminin süresi ve zamanı (gündüz veya gece, çalışma saatleri içinde veya dışında), patlatmaların sıklığı, yerel topluluğun önceden bilgilendirilmesi, alandaki önceki patlatma işlemlerinin gerçekleşmesi ile kişilerin sağlık durumu, mizacı ve yaşı önemli bir rol oynamaktadır (Transport and Road Research Laboratory Department of Transport, 1986). ANSI S3.29-1983, ANSI tarafından geliştirilen bir standarttır. Bu standart 1 saniyeden daha kısa süren titreşimler için gündüz gerçekleştirilen patlatma olay sayısına, zamana (gece veya gündüz) ve lokasyona (konut, ofis) bağlı olarak binadaki insanlar tarafından tolere edilen PPV değerlerini belirtmektedir (Çizelge 5).

Çizelge 5. Binalarda insanlar tarafından tolere edilen PPV değerleri (American National Standards Institute (ANSI), 1983)

Table 5. PPV values tolerated by humans in buildings (American National Standards Institute (ANSI), 1983)

\begin{tabular}{|l|l|l|l|}
\hline Günlük olay sayısı & 1 & 12 & 26 \\
\hline Mesken, gece & $0,2 \mathrm{~mm} / \mathrm{s}$ & $0,09 \mathrm{~mm} / \mathrm{s}$ & $0,07 \mathrm{~mm} / \mathrm{s}$ \\
\hline Mesken, gündüz & $12,70 \mathrm{~mm} / \mathrm{s}$ & $6,35 \mathrm{~mm} / \mathrm{s}$ & $4,30 \mathrm{~mm} / \mathrm{s}$ \\
\hline Ofis ve iş yerleri & $18 \mathrm{~mm} / \mathrm{s}$ & $8,90 \mathrm{~mm} / \mathrm{s}$ & $6,10 \mathrm{~mm} / \mathrm{s}$ \\
\hline
\end{tabular}

\section{İnsan algısı ile yapısal hasar arasındaki ilişki (Relationship between human perception and structural damage)}

Çoğu uluslararası hasar kriterleri, PPV değerinin eşiğinin 5 ila $50 \mathrm{~mm} / \mathrm{s}$ arasında olmasını belirtmektedir. Ancak, insanlar titreşimlere karşı son derece hassastır ve yapısal hasarlara neden olabilecek PPV değerlerinin çok altındaki seviyeleri algılayabilirler. PPV değeri olarak insandaki titreşim algisı 0,02 $\mathrm{mm} / \mathrm{s}^{\prime}$ den, fizyolojik hasar $50 \mathrm{~mm} / \mathrm{s}^{\prime}$ den ve yapısal hasar $5 \mathrm{~mm} / \mathrm{s}^{\prime}$ den başlamaktadır. İnsanlar, 
herhangi bir titreşimin (en düşük seviyelerde olsa bile), yaralanmalara ve yapısal hasarlara yol açacağını varsaydıklarından, korku ve endişe yaşamaktadırlar. Sonuç olarak bu durum şikayetlere neden olmaktadır. Aslında, bir patlama sonucunda algılanan herhangi bir zemin titreşimi, sakinlerin yapılarında hasar korkusu ile çatlaklar aramasına ve çoğu zaman önceden var olan, ancak görmemiş ya da hatırlamadığı çatlaklar buldukça, patlatmayı suçlayıp şikayet etmelerine neden olmaktadır (Transport and Road Research Laboratory Department of Transport, 1986).

\section{Yer Sarsıntısının Yapılar Üzerinde Oluşturduğu Hasarlar (Structural Damages Caused By Ground Vibrations)}

Yer sarsıntılarının neden olduğu yapısal hasarlar 3 ana kategoriye ayrılmaktadır (Işık \& Kuruşcu, 2018; Orica Nitro, t.y):

> Küçük hasar: Kozmetik veya eşik hasar olarak da bilinen küçük hasar, bölme duvarda, sıvada, boyada ve blok malzeme derzlerinde saç teli kalınlığında küçük (kılcal) çatlakların oluşumuna neden olmaktadır. Bu hasar türü sadece yapının görünümünü etkilemektedir.

> Orta hasar: Hafif hasar olarak da bilinen orta hasar, duvarlarda, kirişlerde geniş $(10 \mathrm{~mm})$ çatlakların oluşması ve tavan sıvalarının dökülmesine neden olmaktadır. Ancak bu hasar tipi yapı elemanlarının yük taşıma kabiliyetlerini etkilemez.

> Büyük hasar: Esaslı hasar olarak bilinen büyük hasar, kolon ve kirişlerde çok geniş $(25 \mathrm{~mm})$ çatlakların oluşmasına, bağlantıların gevşemesi, duvar ve bacalardan taş, tuğla düşmesi ve yapıda kalıcı deformasyonlar oluşturarak yapı elemanlarının bozulmasına neden olmaktadır. Bu hasar tipi binanın yük taşıma kabiliyetini etkilemektedir.

Aynı titreşim seviyesine maruz kalan binalar aynı şekilde etkilenmemektedir. Bir binanın titreşim seviyesine gösterdiği hasar tipini etkileyen birçok faktör vardır. Bu faktörler, bölgenin litolojisini, yapının yüksekliğini ve karakteristiklerini (kat sayısı), tabakalarının anizotropisini, binanın teknik özelliklerini, bölgenin fiziko-mekanik özelliklerini, titreşim kaynağının türünü, titreşimin sıklığını, patlatmanın süresini ve patlatma sırasında oluşan sismik dalgalar ile arazi ve yapılar arasındaki etkileşimlerini kapsamaktadir.

Patlatma Kaynaklı Sismik Dalgalar, Arazi Katmanları Ve Yapılar Arasındaki Etkileşimler (Interactions Between Blast-Induced Seismic Waves, Ground Layers And Structures)

Arazi katmanları, titreşim dalgaları ve yapılar arasındaki etkileşimler şunlardır:

> Doğrudan/direkt etkileşim: Yer sarsıntısının şiddeti ve frekansı hasar eşiğinin üzerindeyse hasar meydana gelmektedir.

> Yansıma (Reflection): Yansıma 2 farklı katman arasındaki sınırda meydana gelir ve sınırdaki sismik dalganın birinci ortama kısmen veya tamamen sıçramasına (bouncing) neden olmaktadır (Şekil 3a).

$>$ Kirlma (Refraction): Bu durum 2 ortam arasındaki sinırda meydana gelir ve birinci ortamdan ikinci ortama geçerken hız değişiminin neden olduğu bir dalganın eğilmesine neden olmaktadır (Şekil 3b).

- Kırınım ya da difraksiyon (diffraction): Ortamda bir objenin (bariyer veya küçük açıklık) varlı̆̆ı, sismik dalgaların kırınımına neden olmaktadır (Şekil 3c). 


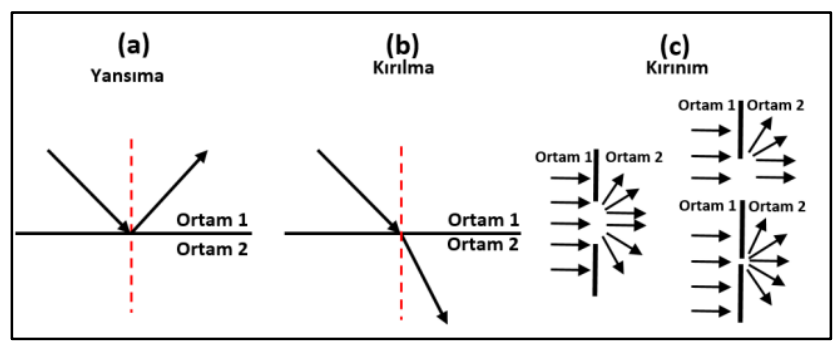

Şekil 3. Yansıma kırılma ve kırınım fenomenleri Figure 3. Reflection, refraction and diffraction phenomena

Rezonans etkisi: Zemin titreşim dalgalarının frekansları ve yapının doğal (özyapısal) frekansları ile örtüşmesi daha büyük bir titreşime neden olabilmektedir. Buna rezonans etkisi (Resonance effect) denir. Rezonans etkisi patlatmadan kaynaklanan yer sarsıntılarının frekans değerleri yapının özyapısal frekans değerlerine yakın olduğunda (genellikle $5-12 \mathrm{~Hz}$ aralığında) meydana gelmektedir (Şekil 4).

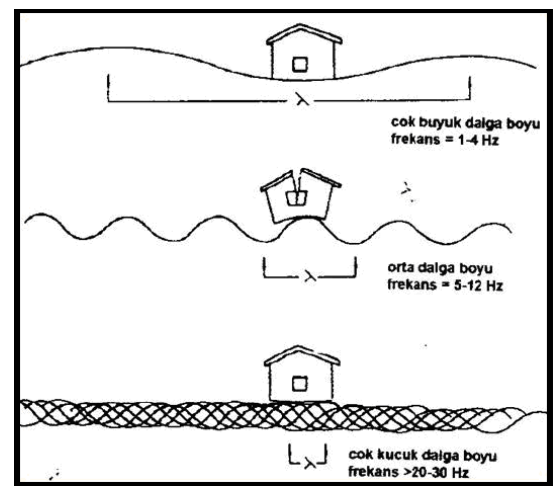

Şekil 4. Farklı frekanslı dalgaların binalar üzerindeki etkileri (Alpaydın et al., 2004) Figure 4. Effect of waves of different frequencies on buildings (Alpaydin et al., 2004)

Patlatma sonucunda oluşan zemin titreşim dalgalarının rezonansa neden olma riski yüksektir, çünkü:

- Genel olarak, bu zemin titreşimleri düşük frekanslar (40 Hz'in altında) sergilemektedir.

- Sismik dalgalar yayılırken yüksek frekanslarını kaybeder.

- Düşük frekanslı dalgalar daha uzun mesafelere ilerler, bu nedenle daha fazla yapıları etkilemektedir.

Yorulma hasarı (Fatigue): Rezonans etkileri uzun bir süre boyunca tekrarlanınca yapının bozulmasına yol açabilmektedir. Buna yorulma hasarı denir.

> Girişim (Interference): Girişim, aynı ortamda aynı anda hareket eden benzer frekansa sahip 2 veya daha fazla dalganın örtüşmesinin sonucudur. Böylece yeni bir dalga oluşturmaktadır. Girişimler daha büyük bir yer sarsıntısı oluşturan yapıcı girişimler (Constructive interferences) veya daha küçük yer sarsıntısı oluşturan yıkıcı girişimler (Destructive interferences) olarak ikiye ayrılmaktadır (Şekil 5). 


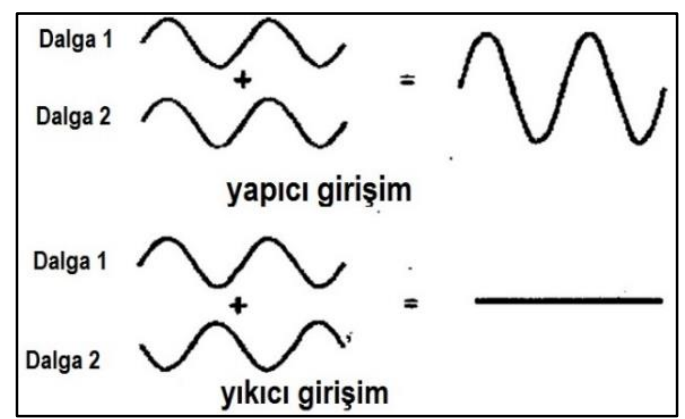

Şekil 5. Yapıcı ve yıkıcı girişimler

Figure 5. Constructive and destructive Interferences

Sönümleme etkisi (the damping effect): Birçok faktör, yer sarsıntısının sönümlenmesini etkilemektedir. Örneğin, kayalar ve yapılar gibi sert malzemeler yüksek oranda aktarıcıdır, yani sönümleme etkileri yumuşak zeminlere kıyasla daha düşüktür. Yumuşak zeminlerde sönümleme etkisi litoloji, kohezyon ve nem seviyesi gibi faktörlere bağlıdır. Örneğin, kumların sönümleme etkileri killerden daha yüksektir. Mesafe gittikçe, yüzey dalgaları cisim dalgalarına nazaran daha az sönümlenir. Yüzey dalgalarının genliği uzaklığa bağlı olarak $1 / \sqrt{r}$ (r kaynak alıcı uzaklık) ile azalır. Oysa cisim dalgaları için genlikteki azalım ise $1 / r$ 'dir (Kaypak, 2019).

\section{PATLATMADAN KAYNAKLANAN YER SARSINTISI HASARININ DEĞERLENDİRME PARAMETRELERİ (ASSESSMENT PARAMETERS OF THE DAMAGES CAUSED BY BLAST-INDUCED GROUND VIBRATION)}

Madencilik faaliyetlerinde patlatma neticesinde oluşan yer sarsıntısının neden olduğu etkileri ve hasarları değerlendirmek için iki ana parametre kullanılmaktadır:

> Bir kinematik tanımlayıcı: Titreşim şiddetini belirlemek için birkaç kinematik tanımlayıcı vardır:

- Parçacık hızı: Maksimum Parçacık hızı (PPV) veya Bileşke Vektörel Toplamı (PVS),

- Parçacık yer değiştirmesi-deplasman (s)

- Parçacık ivmesi (a)

$>$ Frekans $(f)$

Bu parametrelerin aralığ 1 Çizelge 6 'da sunulmuştur.

Çizelge 6. Patlatma parametrelerinin değer aralığ 1 (Nicholson, 2005) Table 6. The value ranges of blasting parameters (Nicholson, 2005)

\begin{tabular}{|c|l|}
\hline Parametre yer değiştirmesi & Değer Aralığı \\
\hline $\begin{array}{c}\text { Parçacık } \\
\text { (deplasman) }\end{array}$ & $0,0001-10 \mathrm{~mm}$ \\
\hline Parçacık hızı & $0,001-1000 \mathrm{~mm} / \mathrm{s}$ \\
\hline Parçacık ivmesi & $10-100000 \mathrm{~mm} / \mathrm{s}^{2}$ \\
\hline Kayı̈t süresi & $0,5-3 \mathrm{~s}$ \\
\hline Dalga boyu & $30-1500 \mathrm{~m}$ \\
\hline Frekans & $0,5-200 \mathrm{~Hz}$ \\
\hline
\end{tabular}

\section{Kinematik Tanımlayıcılar (Kinematic Descriptors)}

Titreşim şiddetlerini tanımlamak için parçacık hızı (Maksimum Parçacık Hızı PPV veya Bileşke Vektörel Toplamı PVS), yer değiştirmesi-deplasman (s) veya parçacık ivmesi (a) kullanılır. Bu parametreler bir sismograf tarafından otomatik olarak belirlenebilmektedir. 


\section{Parçacık hızı: PPV ve PVS (Particle velocity: PPV and PVS)}

Parçacık hızı, titreşim nedeniyle ortamdaki bir taneciğin birim zamandaki yer değiştirmesini (deplasman) temsil eder ve $\mathrm{mm} / \mathrm{s}$ cinsinden ifade edilir. Parçacık hızını belirlemek için Maksimum Parçacık Hızı PPV (Peak Particle Velocity) veya Bileşke Vektörel Toplamı PVS (Peak Vector Sum) kullanılmaktadır.

Maksimum Parçacık hızı (PPV), bir patlatma sonucunda oluşan parçacık titreşiminin (enine, düşey ve boyuna) üç bileşenini simultane olarak ölçerek ve maksimum değeri alınarak belirlenir. Ancak, Bileşke Vektörel Toplamı (PVS) enine, düşey ve boyuna düzlemler boyunca oluşan maksimum parçacık hızlarının karelerinin toplamının kareköküdür ve aşağıdaki denklem kullanılarak hesaplanmaktadır.

$\mathrm{PVS}=\sqrt{\mathrm{T}_{\mathrm{p}}^{2}+\mathrm{V}_{\mathrm{p}}^{2}+\mathrm{L}_{\mathrm{p}}^{2}}$

Burada; $T_{p}, V_{p}$ ve $L_{p}$ sirasıyla enine, düşey ve boyuna düzlemler boyunca maksimum parçacık hızıdır.

Her ikisi de parçacık hızını temsil etse de, PPV ve PVS oldukça farklıdır. PPV vektörel bir büyüklük, yani bir değere ve bir yöne sahiptir. Ancak, PVS skaler bir büyüklüktür çünkü sadece bir değere sahiptir. Ayrıca, aynı patlatma projesi için, zemin titreşim hasarları değerlendirilirken PVS değerleri PPV değerlerinden genellikle daha büyüktür. Bu nedenle bazı çalışmalar, (Torres et al., 2018) titreşim hasarlarının incelemesinde PVS' nın daha güvenli bir parametre olduğunu savunmaktadır. Aynı zamanda PVS, PPV tarafından göz ardı edilen diğer iki bileşenin etkilerini dikkate almaktadır. Ancak, bazı araştırmacılar titreşim hasarlarını değerlendirmek için PPV'yi en iyi gösterge olarak tanımlar çünkü parçacık ivmesi ve deplasman gibi yer hareket parametreleri ile iyi bir korelasyon göstermektedir.

\section{Parçacık yer değiştirmesi-deplasman (Particle displacement)}

Parçacık yer değiştirmesi (particle displacement s), zemin titreşimine maruz kalan bir parçacığın başlangıç noktasına (referans konumu) olan mesafesidir (Çağlar, 2008). Bu parametre (s) olarak tanımlanır ve $(\mathrm{mm})$ cinsinden ifade edilir. Parçacık deplasmanı, hızın zaman ile çarpılmasıyla elde edilir.

\section{Parçacık İvmesi (Particle acceleration)}

Parçacık ivmesi (acceleration, a) birim zamanda parçacı̆̆ın hız değişim oranını belirtmektedir ve $\left(\mathrm{mm} / \mathrm{s}^{2}\right)$ veya $(\mathrm{g})$ cinsinden ifade edilir. Bu parametre, hızdaki farkı zamandaki farka bölerek sismograf tarafından hesaplanabilir. Aynı zamanda parçacık ivmesi maksimum parçacık hızı (PPV) ve frekans $(f)$ kullanılarak aşağıdaki belirtilen denklemle de hesaplanabilmektedir:

$\mathrm{a}=2 \pi v f$ 2017)

a: parçacık ivmesi (mm.s. $)$, v: PPV (mm.s. s $^{-1}$ ve f: frekans $(\mathrm{Hz})$ (Avellan, Belopotocanova, \& Puurunen,

Ancak hesaplanan değerler, genellikle titreşim dalgası mükemmel bir sinüzoidal dalga olmadığı için ölçülenlerden daha düşüktür. Bazı referanslar, potansiyel olarak hasara neden olabilecek parçacık ivmesinin değerini $0,159 \mathrm{~g}$ ( $\mathrm{g}$ yerçekimi ivmesidir, $\mathrm{g}=9.81 \mathrm{~m} / \mathrm{s}^{2}$ ) olarak belirtmektedir.

\section{Frekans (Frequency)}

Frekans, bir saniyedeki titreşim dalga sayısı olarak tanımlanmaktadır ve $(\mathrm{Hz})$ cinsinden ifade edilir. Patlatma neticesinde oluşan yer sarsıntılarının yapısal hasarlarını ve potansiyel şikayetleri önlemek için, oluşan frekansların dağılımını incelemek en önemli unsurlardan biridir.

Patlatma faaliyetlerinden oluşan zemin titreşim frekanslarının çoğu 40 Hz'in altındadır. Şekil 6' da iki farklı açık ocakta patlatmalar neticesinde yayılan zemin titreşim frekanslarının dağılımı sunulmaktadır.

Birleşik devletler maden bürosu (USBM), frekansları düşük ve yüksek frekanslar olarak sınıflandırır ve düşük frekansları $(<40 \mathrm{~Hz})$ daha zarar verici olarak tanımlamaktadır. Düşük frekanslar, yüksek frekanslardan daha az sönümleme etkisine maruz kaldıklarından dolayı daha ileri mesafelere gidebilmektedirler (Siskind, Stagg, Kopp, \& Dowding, 1980). Ayrıca, $10 \mathrm{~Hz}$ değerinin altındaki frekanslar 
hasar olasılığını artırmaktadır (Siskind et al., 1980). Patlatmalar sonucunda oluşan yer sarsıntısının düşük frekansları, bir veya iki katlı binalarda genellikle $5-10 \mathrm{~Hz}$ arasında değişen bina özyapısal frekanslarıyla (Erçikdi et al., 2004) etkileşime girebilir ve eğer bu frekanslar binanın özyapısal frekanslarına eşit veya biraz daha yüksek ise rezonans etkisine sebep olmaktadır. Böylece hasar eşik değerine ulaşıldığında yapısal hasarlara, eşik değere ulaşılmazsa bile insan rahatsızlığına neden olabilirler.

İnsanlar düşük frekansları kolayca algılayabilir ancak yüksek frekansları neredeyse hiç algılayamaz. $\mathrm{Bu}$ düşük frekanslar $(<40 \mathrm{~Hz})$ zarar verici etkilere sahip olmasına rağmen, insanlar tarafından kolay algılandığı için yapılara sürekli zarar verdiği izlenimi oluşur. Bu nedenle patlatma neticesinde oluşan hasarlar analiz edildiğinde, uluslararası standartların belirlediği hasar verme eşik seviyelerinden az olsa bile yüksek şikayet sayısına neden olabilmektedir.

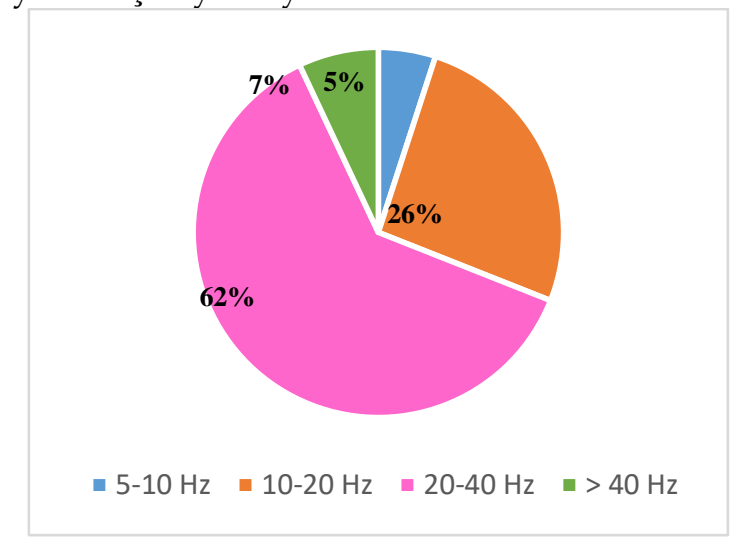

(a) Açık ocak (Siskind et al., 1980)

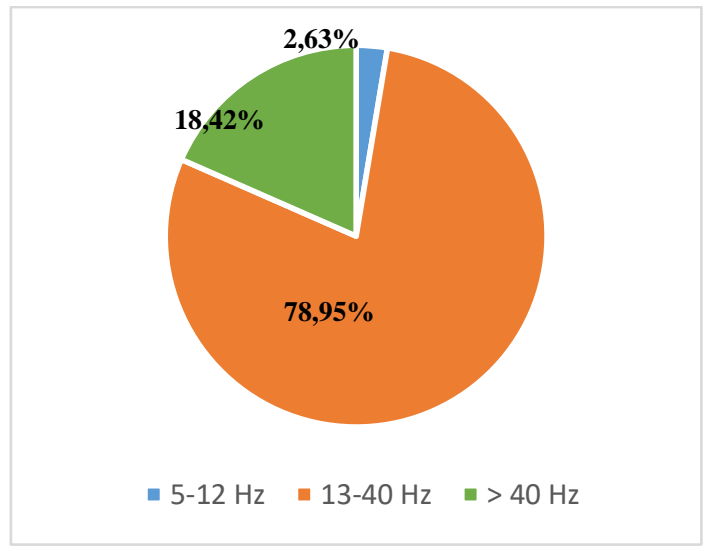

(b) Arakl1-Taşönü kireçtaşı ocağı (Erçikdi et al., 2004)

Şekil 6. Farklı iki açık ocakta patlatma sonucunda oluşan yer sarsıntısının frekans dağılımı Figure 6. The frequency distribution of blast-induced ground vibrations in two different open pit quarries

\section{YER SARSINTISININ ÖLÇÜMÜ VE İZLEME SİSTEMİ (MEASURING AND MONITORING SYSTEM OF GROUND VIBRATION)}

İlk zemin titreşim ölçüm cihazlarının ortaya çıkışı 19. yüzyılın başlarına dayanmaktadır. Patlatma sonucunda oluşan yer sarsıntısının ilk ölçümleri 1919'da Rockwell tarafından yapılmıştır (Taqieddin, 1986). Bu ölçümlerin sonuçları Rockwell tarafından 1927'de bildirilmiştir. Ardındançeşitli cihazlar gelişmeye devam etmiştir.

Günümüzde hem jeofon ve mikrofon hem de izleme sistemleri ve yazılımları kullanarak hava şoku ve zemin titreşimi ölçmeyi ve kontrol etmeyi sağlayan gelişmiş sismograflar mevcuttur(Şekil 7).

Zemin titreşimleri kapsamında, sismograflar her bir patlatma olayı için zaman esaslı olarak parçacık hızı bileşenlerini (enine, düşey ve boyuna), frekans, maksimum parçacık hızı (Peak Particle Velocity PPV), bileşke Vektörel Toplamı (Peak Vector Sum PVS), maksimum deplasman ve maksimum parçacık ivmesini kaydetmektedir. Ölçümlerin hassas ve güvenilir bir şekilde yapılabilmesi için cihaza bağlanan jeofon ve mikrofon her türlü zeminde hareket etmeden (sabit) kalacak şekilde kurulmaktadır (Yılmaz, 2017). 


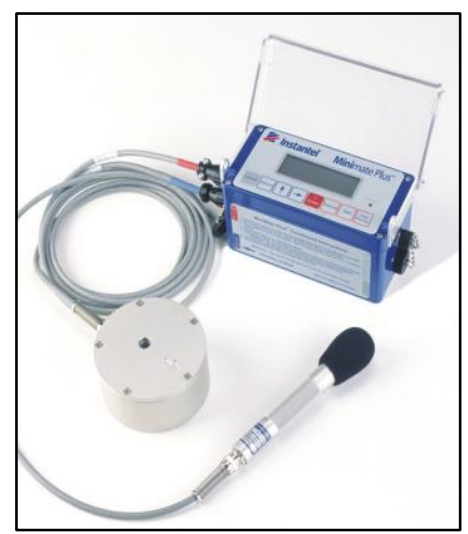

Şekil 7. Instantel Minimate Plus (Instantel)

Figure 7. Instantel Minimate Plus (Instantel)

\section{SONUÇLAR (CONCLUSIONS)}

İnsan yapımı titreşim kaynakları incelendiğinde çeşitli alanlarda ve özellikle madencilik faaliyetlerinde yoğun olarak kullanılan patlayıcı maddeler ana endişe kaynağıdır. Patlatma işlemleri, en tehlikeli zemin titreşim kaynağıdır ve dolayısıyla insan rahatsızlıkları ile esaslı hasarların ardındaki sayısız şikâyetlerin ana sebebi olarak öne çıkmaktadır. Böylece, kişisel ve yapısal etkileri önlemek için patlatma sonucunda oluşan yer sarsıntısının değerlendirilmesi, şev stabilitesi, gaz ve petrol boru hatlarının güvenliği, anıtlar ve tarihi binalar, barajlar, köprüler, nükleer yapılar ve yeraltı depoları gibi birçok tasarımın korunmasında önemlidir. Bunun sebebi, yer sarsıntılarının, patlatmadan kaynaklanan diğer etkilere nazaran çok daha uzak mesafelere ulaşabilmesi, yani daha büyük bir bölgeyi etkilemesidir. Ayrıca patlatma kaynaklı yer sarsıntılarının, deprem dalgaları ile benzer hareket etmeleri yapılar üzerindeki hasar etkilerini arttırmaktadır.

Yer sarsıntısı insan rahatsızlığına, hassas ekipmanların arızalanmasına, yapısal hasarlara ve hatta can kayıplarına neden olabilmektedir. Bu sebeple, madencilik ve inşaat kazılarının temelini oluşturan patlatma faaliyetleri sonucu ortaya çıan zemin titreşimlerinin takip ve kontrol edilmesi özel irdelenmesi gereken konular arasındadır. Bu yüzden, yer sarsıntılarının zararlı etkilerini en aza indirmek, insan rahatsızlığı ve yapısal hasarları önlemek için patlatma sırasında oluşan sismik dalgaların yayılım mekanizmalarının araştırılması son derece önemlidir. Ayrıca insanlar, evlerinin patlatma kaynaklı yer sarsıntılarından dolayı hasar gördüğünü iddia etmekte ve bunu dava konusu yaparak işletmelerden tazminat talebinde bulunmaktadır. Bu iddiaların yersiz olduğu, çeşitli nedenlerden (zemin oturması, yaşlanma, heyelan) dolayı oluşan hasarların patlatma faaliyetlerine atıf edildiği sık karşılaşılan bir durumdur. Bu nedenle patlatma kaynaklı yer sarsintılarının takip ve kontrol edilmesi ve hasar analizlerinin uzman kişilerce değerlendirilmesi gerekmektedir.

\section{KAYNAKLAR (REFERENCES)}

Aksoy, C.O., Yalçın, E., 1999, Kırmataş Üretim yöntemlerinin Ekonomik Analizi, 3. Endüstriyel Hammaddeler Sempozyumu, İzmiri Türkiye

Alpaydın, E., Alpsar, M., Elmacı, E., Hahıcılar, G., İnal, H. S., İşcen, H. İ., Patır, O., ve Özkazanç, M.Ö., 2004, Patlayıcı maddeler ve patlatma teknikleri, Nitromak, Ankara, s. 129.

American National Standards Institute, 1983, Guide to the Evaluation of Human Exposure to Vibrations in Buildings, ANSI S3.29-1983, p.10.

Avellan, K., Belopotocanova, E., \& Puurunen, M., 2017, Measuring, monitoring and prediction of vibration effects in rock masses in near-structure blasting, Procedia Engineering, 191, 504-511. 
Bilim, N., Kekeç, B., 2017, Patlatma Kaynaklı Çevresel Etkiler ve Önlenmesi İçin Alınması Gereken Tedbirler, International Symposium on Mining and Environment (ISME 2017), 27-29 Sept. 2017, Bodrum-Turkey

Bormann, P., 2012, New Manual of Seismological Observatory Practice 2 (NMSOP2), GFZ German Research Centre for Geosciences, Potsdam, 33-103.

Cevizci, H., 2013, New Approach On Blasting For Excavation, SDU International Technologic Science, Vol. 5, No 1, pp. 104-111

Çağlar, S., 2008, Orman yolları yapımında kaya patlatma tekniği ve çevresel etkileri üzerine bir araştırma, Doktora Tezi, Karadeniz Teknik Üniversitesi Fen Bilimleri Enstitüsü, Trabzon, 29-34.

Dowding, C. H., 1985, Blast vibration monitoring and control, Prentice Hall, Inc, Englewood Cliffs, NJ, p. 297.

Duarte, M. L. M., Misael, M. R., \& Filho, L. E. F., 2002, Experimental evaluation of vibration comfort for a residential environment, Proceedings of SPIE, The International Society for Optical Engineering 4753, 1376-1381.

Elevli, B., \& Arpaz, E., 2010, Evaluation of parameters affected on the blast induced ground vibration (BIGV) by using relation diagram method (RDM), Acta Montanistica Slovaca Ročník, 15 (4), 261-268.

Erçikdi, R., Kesimal, A., Yılmaz, E., \& Cihangir, F., 2004, Patlatma kaynaklı yersarsıntısı ölçüm sonuçlarinin değerlendirilmesi, Dumlupınar Üniversitesi Fen Bilimleri Enstitüsü Dergisi, 7, 195-215.

Ghiloufi, D., 2020, Farklı Zeminlerin Yer Titreşim Dalgalarının Yayılım Mekanizması Üzerindeki Etkilerinin İncelenmesi, Yüksek Lisans Tezi, Konya Teknik Üniversitesi, Konya, s. 111

International Organisation for Standardisation, 2010, Mechanical vibration and shock - Vibration of fixed structures -guidelines for the measurement of vibrations and evaluation of their effects on structures, ISO 4866, Geneva, Switzerland.

Işık, M. E., \& Kuruşcu, A. O., 2018, Yapısal titreşimlerin kullanıcı konforuna etkisinin incelenmesi, Harran Üniversitesi Mühendislik Dergisi, 01, 20-34.

Kaypak, B., 2019, Sisimik dalgalar (Yüzey dalgaları) [online], Ankara Üniversitesi, https://acikders.ankara.edu.tr/mod/resource/view.php?id=95608 [Ziyaret Tarihi: 25 Şubat 2019]

Moğulkoç, Y., Çıldıroğlu, H.A., 2017, Fizik Laboratuvar Ders Notları, Ankara Üniversitesi Mühendislik Fakültesi, Ankara, s.65

Nicholson, R. F., 2005, Determination of Blast Vibrations Using Peak Particle Velocity at Bengal Quarry, in St Ann, Jamaica, Master's Thesis, Lulea University of Technology, 33-41.

Oriard, L. L., \& Emmert, M. W., 1980, Short-delay Blasting at Anaconda's Berkeley Open-pit Mine, AIME Annual Meeting, Las Vegas, NV, 60-80.

Orica Nitro., t.y., Case Study Selection of Blasting Limits for Quarries and Civil Construction Projects, ORICA-NITRO, p. 14.

Peng, Y., Wenbo, L., Jing, Z., Yujun, Z., \& Ming, C., 2017, Evaluation of human response to blasting vibration from excavation of a large scale rock slope: A case study, Earthquake Engineering and Engineering Vibration, 16 (2), 435-446.

Siskind, D. E., Stagg, M. S., Kopp, J. W., \& Dowding, C. H., 1980, Structure response and damage produced by ground vibration from surface mine blasting, U.S. Bureau of Mines, p. 84

Society of Explosive Engineers, t.y., Human perception [online], https://explosives.org/vibrationbasics/human-perception/ [Ziyaret Tarihi: 05 Ağustos 2019]

Srbulov, M., 2008, Geotechnical earthquake engineering: Simplified analyses with case studies and examples, Springer Science \& Business Media, Berlin, p. 244.

Singh, N.T., 2012, New Trends in Economical and Safe Rock Blasting, J Powder Metall Min. V. 1:1, http://dx.doi.org/10.4172/2168-9806.1000e104

Taqieddin, S. A., 1986, Ground vibration levels: Prediction and parameters, Mining Science and Technology, 3, 111-115. 
Torres V.F., N., Silveira, L. G. C., Lopes, P. F. T., \& M. de Lima, H., 2018, Assessing and controlling of bench blasting-induced vibrations to minimize impacts to a neighboring community, Journal of Cleaner Production, 187, 514-524.

Transport and Road Research Laboratory, 1986, Ground vibration caused by civil engineering works, Department of Transport, Research report 53, Crowthorne, Berkshire, p. 19.

Wu, X., \& Wu, R. S., 2008, Handbook of Signal Processing in Acoustics, Springer, New York, NY, 15351544.

Yılmaz, T., 2017, Maden İşletme laboratuvari -2 deney adı: Delme - Patlatma ve çevresel etkileri [online], Konya Teknik Üniversitesi, http://www.ktu.edu.tr/dosyalar/maden 9137e.pdf 